\title{
Surgical management of malignant gastric GIST with organ sparing surgery
}

\author{
Gagan Soni*, Kumar Krishna B, Asma Khalife, Bhushan Telang, Deepak Ranvir and Rajeev Joshi \\ Department of General Surgery, Topiwala National Medical College \& B.Y.L. Nair Ch. Hospital, Mumbai, Maharashtra, India
}

\begin{abstract}
Background: Gastrointestinal stromal tumours (GISTs) are rare mesenchymal tumours located commonly in the stomach. A complete and radical surgery is needed in most cases. GISTs near the gastro-esophageal junction are more challenging as compared to those situated in the pylorus, because of the complex surgical management. In our case we attempted an organ sparing surgery for a tumour located on the lesser curvature, which was close to cardia, thus avoiding a radical gastrectomy.
\end{abstract}

Methods: A midline laparotomy followed by creation of a sleeve of the greater curvature was done. The cardio-oesophageal junction was divided and the tumour along with stomach adjacent to the lesser curvature resected using gastro-intestinal anastomotic linear staplers. Once vascularity of remnant stomach was confirmed, the greater curvature remnant was anastomosed to the oesophagus, thus restoring anatomic continuity.

Results: Post-operative recovery was uneventful. A contrast study done on post-operative day 8 showed no leak. Patient was started on orals and was discharged on day 10 after adequate oral intake. Final histopathology report revealed a spindle cell GIST with resection margins and lymph nodes uninvolved. Immunohistochemistry study was positive for C-Kit and DOG-1 and negative for desmin and S-100. Tablet Imatinib was started and on a six month follow up patient showed no evidence of recurrence.

Conclusions: GIST of lesser curvature close to cardia, can be treated with organ sparing surgery in selected patients, provided adequate tumour free resection margins and vascularity of remnant stomach is possible. It avoids a radical surgery and its associated complications.

\section{Introduction}

GIST is a rare tumour of alimentary canal (0.1-3\%) arising from the interstitial cells of Cajal. It is most commonly found in the stomach (50$70 \%)$ and if left untreated it can bleed or rupture [1]. It may also present with obstruction, perforation and peritoneal or distant metastases.

We present a case of lesser curvature GIST for which a greater curvature sparing gastrectomy is done. To our knowledge, greater curvature preserving gastrectomy for GIST is rare in literature.

\section{Case report}

A 55-year gentleman presented with complains of epigastric and left hypochondrium pain for 3 months. It was insidious in onset and gradually increasing, accompanied with weight loss and anorexia but no vomiting or hematemesis. On abdominal examination, he had $3 \times$ $3 \mathrm{~cm}$, smooth, mobile, hard lump in the epigastrium with well-defined margins and moving with respiration. Contrast enhanced computed tomography (CECT) abdomen revealed a circumferential mural thickening of 1-3 cm involving distal oesophagus for length of $8 \mathrm{~cm}$ below gastroesophageal (GE) junction and a large ulcero-proliferative growth involving cardia and lesser curvature of stomach of thickness $2 \mathrm{~cm}$. It also had exophytic component of $6 \times 5 \times 4 \mathrm{~cm}$ in fundus and cardia (Figure 1). Endoscopy findings corroborated with CT findings and a targeted biopsy was taken which was reported as spindle cell GIST. Patient was posted for elective surgery.

\section{Method}

A midline laparotomy was done. The intra-operative findings (Figure 2A) were a $4 \times 4 \mathrm{~cm}$ hard mass in the stomach and a $5 \times 7$ cm lymph node along lesser curvature and enlarged coeliac group of lymph nodes. There were no peritoneal deposits, ascites or liver nodules and rest of bowel loops, omentum and mesentry was normal.

A formal resection of distal oesophagus of a length of $4 \mathrm{~cm}$ from the GE junction along with fundus, lesser curvature containing the tumour and lymph nodes was done after ligating the left gastric and left gastro-epiploic vessels (Figure 2B). Care was taken to preserve the vascularity of the greater curvature by sparing the right gastric and right gastro-epiploic vessels, thereby creating a gastric conduit of the greater curvature. Once vascularity was confirmed (Figure 2C), a handsewn esophago-gastric anastomosis is fashioned.

\section{Results}

A contrast study done on post-operative day 8 showed no evidence of leak or hold up (Figure 3). The patient was then gradually started on orals and discharged once full diet was tolerated. Final histopathology report was spindle cell GIST with resection margins and lymph nodes free of tumour. Immunohistochemistry study showed tumour positive for C-Kit and DOG-1 and negative for desmin and S-100. Patient was

${ }^{*}$ Correspondence to: Gagan Soni, Department of General Surgery, Topiwala National Medical College \& B. Y. L. Nair Ch. Hospital, Mumbai, Maharashtra, India, Tel: +91-8839083626; E-mail: sonigagan90@gmail.com

Key words: gastrointestinal stromal tumours, organ preserving surgery

Received: July 04, 2019; Accepted: July 18, 2019; Published: July 22, 2019 


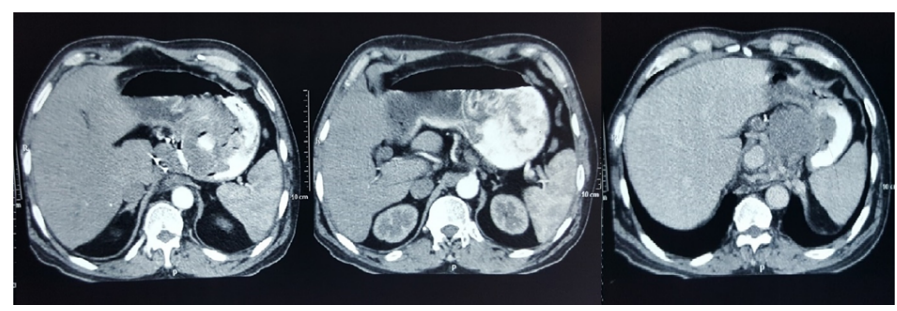

Figure 1. CECT findings of circumferential growth with exophytic component along the lesser curvature and cardia

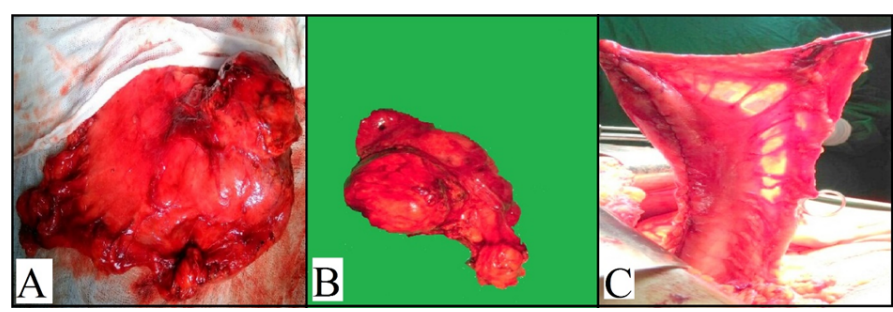

Figure 2. (A) Intraoperative in-situ picture of the mass (B) Resected specimen (C) Vascularity of the remnant greater curvature

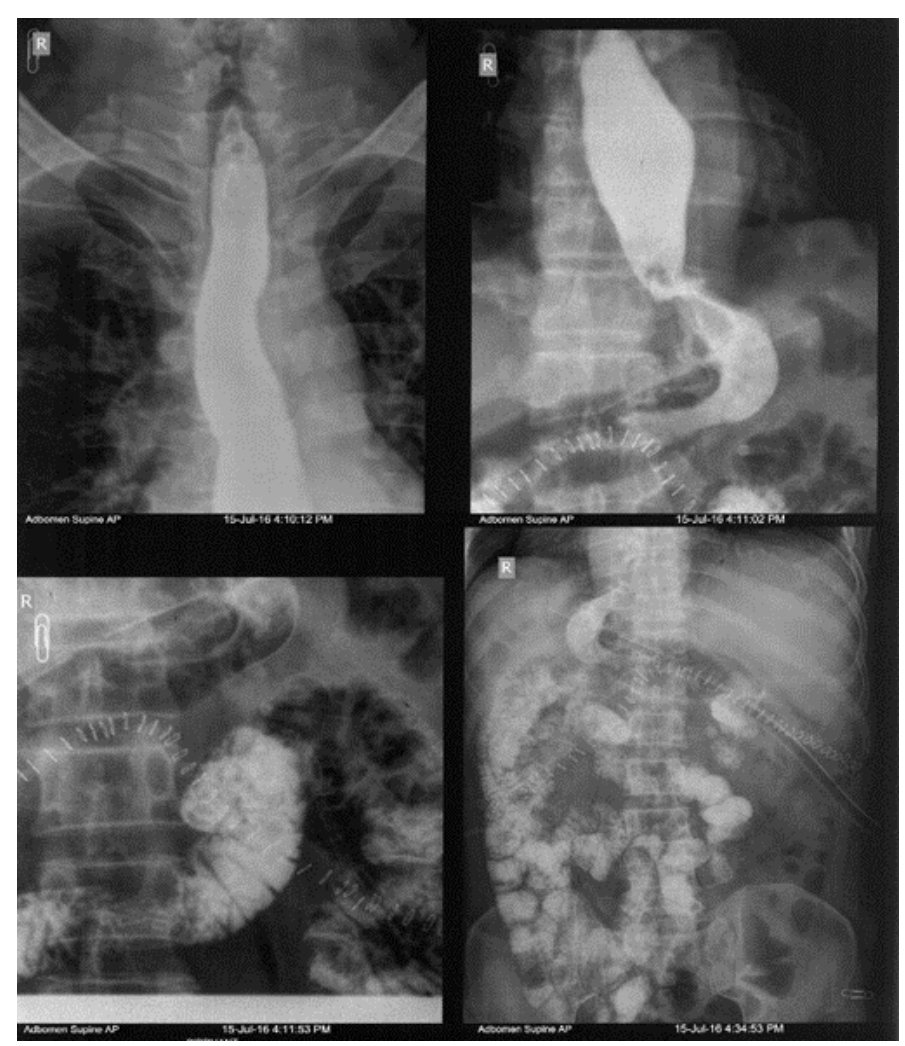

Figure 3. Smooth passage of dye into duodenum and then into small bowel

started on tablet Imatinib 400mg once a day. On six months follow up, patient showed no evidence of recurrence.

\section{Discussion}

Gastrointestinal stromal tumours (GISTs) are the most common mesenchymal neoplasms, with a global annual incidence of 10-15 cases per million [2-4]. GISTs represent a wide clinical spectrum of tumours arising throughout the gastrointestinal tract. They are located typically in the submucosa of the stomach (50-70\%) and the small (20-30\%) and large intestines (5\%), although cases arising in the oesophagus $(<5 \%)$, greater omentum, and mesenterial adipose tissue have been described [5].

In the early literature, these tumours used to be classified as leiomyoma, cellular leiomyoma, leiomyoblastoma, and leiomyosarcoma, but in the 1960s, electron microscopic studies revealed the lack of typical smooth muscle differentiation in some of these gastric tumours. Subsequently, leiomyomas, which did not exhibit ultrastructural characteristics of smooth muscle cells and lacked immunohistochemical features of Schwann cells (i.e., no expression of S-100 protein), were classified as "gastric stromal tumours" by Mazur and Clark in 1983 [6]. GIST is currently defined as tumours whose behaviour is driven by mutations in the KIT gene expressing the CD 117 antigen (85\%), PDGFRA gene (10\%) or BRAF kinase (rare) [7].

GIST arises from the interstitial cells of Cajal, which are located in the submucosal and myenteric plexus of the gastrointestinal tract. The majority of these are benign and asymptomatic. They may occasionally present as symptoms of obstruction, compression or haemorrhage. Haemorrhage is the most common symptom of malignancy. The most important prognostic factors determining the malignant potential of GISTs are tumour size (poor prognosis if $>5 \mathrm{~cm}$ ), mitotic count (expressed as the number of mitoses on a total area of $5 \mathrm{~mm}^{2}$ ) and tumour site $[8,9]$. Tumour rupture has also been identified as an additional adverse prognostic factor [10]. The preferred imaging modalities in the evaluation are CECT and MRI.

A GIST of any size should be excised to eliminate the need for serial endoscopy and prevent the progression of symptoms. The only curative treatment is complete surgical resection. The aim is a complete gross resection, with negative microscopic margins and intact pseudo-capsule, to avoid tumour rupture and intraperitoneal dissemination [11]. Treatment could be either a local excision with a 2-4 cm margin, enucleation or a stapled gastric resection depending on the nature of the tumour. GIST is known to rarely metastasize to lymph nodes and therefore regional lymphadenectomy is generally not required. Furthermore, organ-sparing resection (segmental resection) is oncologically appropriate and should be aimed for. When the tumour attaches to other organs, en-bloc resection is appropriate. Intraperitoneal rupture or bleeding is associated with a high risk of postoperative recurrence of nearly $100 \%[12,13]$. Therefore, it is of critical importance that the GIST, which is soft and fragile in nature, should not rupture intraoperatively demanding special care while handling the tumour.

A surgical approach may be laparoscopic or open or combined laparoscopic and endoscopic. Position of the lesion plays an important factor in determining the approach. The decision of appropriate laparoscopic surgery is affected by tumour size, location, and growth pattern [14]. Anterior wall lesions and those situated along the curvatures generally undergo wedge resection. Posterior wall lesions undergo a gastrostomy and resection. For tumours located at the cardia, laparoscopic gastric resection is difficult one. Due to its location, resection with sufficient margins is not possible without compromising the Angle of His and the muscle layers that construct the anti-reflux mechanism. The deformity after resection of a lesion in the gastric fundus and cardia can result in gastroesophageal reflux or stenosis.

Our case of malignant lesser curvature GIST near GE junction mandated a radical gastrectomy. We proceeded with an intention of radical surgery however intra-operatively we were able to get an adequate resection margin and there was no evidence of local invasion 
or metastasis. The greater curvature sparing 'sleeve' conduit helped prevent a proximal gastrectomy.

Locally advanced primary GISTs deemed unresectable are currently treated with neoadjuvant therapy, and surgery is offered to cases in which the medical therapy renders the GIST resectable. Surgery in metastatic or recurrent GISTs is more controversial and case selection is critical. It can be offered to patients whose disease is responding to medical management or to those with limited focal progression, although impact on progression-free survival and overall survival are unknown. Palliative surgery can also be considered in symptomatic patients [15].

Radiotherapy and chemotherapy have not been effective for GISTs [16] with responses in less than 5\% [17]. However, tyrosine-kinase inhibitors, such as imatinib, sunitinib, and regorafenib have been used with success. Imatinib, an orally administered drug initially marketed for chronic myelogenous leukaemia based on bcr-abl inhibition, also inhibits both c-kit tyrosine kinase mutations and PDGFRA mutations other than D842V, is useful in treating GISTs in several situations. The Scandinavian-German SSG XVIII study (2012) suggested that adjuvant therapy with imatinib for 3 years increases recurrence free and overall survival $[18,19]$.

Often majority of GIST tumours are cured by surgery, and do not need adjuvant therapy $[20,21]$. Cases of histopathologically proven malignancy, intraoperative spillage, local invasion or positive margins mandate adjuvant therapy. Cases where the anatomical position of the tumour results in a technically difficult or complex surgery can benefit from neo-adjuvant therapy. For example, rectal GIST often requires radical surgery, often involving abdominoperineal resection and a permanent stoma. In these situations, the use of neoadjuvant imatinib can significantly decrease both tumour size and mitotic activity and permit less radical sphincter-preserving surgery [22].

A study of 1000 patients by Cavnar and Michael J. et all revealed that patients treated in the imatinib era had prolonged survival across all presentations when compared to the pre-imatinib era. In the imatinib era, among site, size, and mitotic rate, high-risk features were associated with treatment with the drug, but only size $>10 \mathrm{~cm}$ correlated with increased survival and recurrence free survival [23].

In resistant cases, patients do benefit from sorafenib therapy after imatinib/sunitinib failure with survival of more than 1 year and it can be postulated that sorafenib can be a substitute of regorafenib in the third line therapy of advanced GIST [24].

\section{Conclusion}

GIST, a mesenchymal tumour of alimentary canal often requires a radical surgery. If located on the lesser curvature, a greater curvature sparing gastrectomy can be done with esophago-gastric anastomosis thus preserving normal conduit. This results in a better outcome in selected patients thus avoiding a morbid procedure.

\section{References}

1. Skandalos IK, Hotzoglou NF, Matsi KCh, Pitta XA, Kamas AI (2013) Giant extra gastrointestinal stromal tumour of lesser omentum obscuring the diagnosis of a choloperitoneum. Int J Surg Case Rep 4: 818-821.

2. Rubin BP, Heinrich MC, Corless CL (2007) Gastrointestinal stromal tumour. Lancet 369: 1731-1741. [Crossref]

3. Mucciarini C, Rossi G, Bertolini F, Valli R, Cirilli C, et al. (2007) Incidence and clinicopathologic features of gastrointestinal stromal tumours. A population-based study. BMC Cancer 7: 230. [Crossref]
4. Nilsson B, Bümming P, Meis-Kindblom JM, Odén A, Dortok A, et al. (2005) Gastrointestinal stromal tumours: the incidence, prevalence, clinical course, and prognostication in the preimatinib mesylate era-a population-based study in western Sweden. Cancer 103: 821-829. [Crossref]

5. Miettinen M, Lasota J (2001) Gastrointestinal stromal tumours - definition, clinical, histological, immunohistochemical, and molecular genetic features and differential diagnosis. Virchows Arch 438:1-12. [Crossref]

6. Mazur MT, Clark HB (1995) Gastric stromal tumours: reappraisal of histogenesis. Am J Surg Pathol 19: 207-216. [Crossref]

7. Demetri G. DeVita L, Lawrence TS, Rosenberg SA editors (2011). "Chapter 87" DeVita, Hellman, and Rosenberg's Cancer: Principles and Practice of Oncology (9th ed.). ISBN 978-1-4511-0545-2.

8. Miettinen M, Lasota J (2006) Gastrointestinal stromal tumours: pathology and prognosis at different sites. Semin Diagn Pathol 23: 70-83. [Crossref]

9. Edge SB, Compton CC (2010) The American Joint Committee on Cancer: the 7th edition of the AJCC cancer staging manual and the future of TNM. Ann Surg Oncol 17: 1471-1474. [Crossref]

10. Takahashi T, Nakajima K, Nishitani A, Souma Y, Hirota S, et al. (2007) An enhanced risk-group stratification system for more practical prognostication of clinically malignant gastrointestinal stromal tumours. Int J Clin Oncol 12: 369-374. [Crossref]

11. Mazzocca A, Napolitano A, Silletta M, Spalato Ceruso M, Santini D, et al. (2019) New frontiers in the medical management of gastrointestinal stromal tumours. Ther Adv Med Oncol 11: 1758835919841946. [Crossref]

12. Bedard EL, Mamazza J, Schlachta CM, Poulin EC (2006) Laparoscopic resection of gastrointestinal stromal tumours: not all tumours are created equal. Surg Endosc 20: 500-503. [Crossref]

13. Bamboat ZM, Dematteo RP (2012) Updates on the management of gastrointestinal stromal tumours. Surg Oncol Clin N Am 21: 301-316. [Crossref]

14. Lee CH, Hyun MH, Kwon YJ, Cho SI, Park SS (2012) Deciding Laparoscopic Approaches for Wedge Resection in Gastric Submucosal Tumours: A Suggestive Flow Chart Using Three Major Determinants. J Am Coll Surg 215: 831-840. [Crossref]

15. Ford SJ, Gronchi A (2016) Indications for surgery in advanced/metastatic GIST. Eur J Cancer 63: 154-167. [Crossref]

16. Kantarjian HM, Wolff RA, Koller CA (2011) The MD Anderson Manual of Medical Oncology (2nd ed.). McGraw-Hill. ISBN 978-0-07-170106-8.

17. Demetri G. DeVita L, Lawrence TS, Rosenberg SA, editors (2011). "Chapter 87" DeVita, Hellman, and Rosenberg's Cancer: Principles and Practice of Oncology (9th ed.). ISBN 978-1-4511-0545-2

18. Cohen MH, Johnson JR, Justice R, Pazdur R (2012) Approval summary: imatinib mesylate for one or three years in the adjuvant treatment of gastrointestinal stromal tumours. Oncologist 17: 992-997. [Crossref]

19. Joensuu H, Eriksson M, Sundby Hall K, Hartmann JT, Pink D, et al. (2012) One vs three years of adjuvant imatinib for operable gastrointestinal stromal tumour: a randomized trial. JAMA 307: 1265-1272. [Crossref]

20. Joensuu H (2012) Adjuvant treatment of GIST: patient selection and treatment strategies. Nat Rev Clin Oncol 9: 351-358. [Crossref]

21. Joensuu H (2012) Adjuvant therapy for high-risk gastrointestinal stromal tumour: considerations for optimal management. Drugs 72: 1953-1963. [Crossref]

22. Wilkinson MJ, Fitzgerald JE, Strauss DC, Hayes AJ, Thomas JM, et al. (2015) Surgical treatment of gastrointestinal stromal tumour of the rectum in the era of imatinib. $\mathrm{Br} J$ Surg 102: 965-971. [Crossref]

23. Cavnar MJ, Seier K, Curtin C, Balachandran VP, Coit DG, et al. (2019) Outcome of 1000 Patients with Gastrointestinal Stromal Tumour (GIST) Treated by Surgery in the Pre and Post-imatinib Eras. Ann Surg. [Crossref]

24. Rutkowski P, Jagielska B, Andrzejuk J, Bylina E, Lugowska I, et al. (2017) The analysis of the long-term outcomes of sorafenib therapy in routine practice in imatinib and sunitinib resistant gastrointestinal stromal tumours (GIST). Contemp Oncol (Pozn) 21: 285-289. [Crossref]

Copyright: (C2019 Soni G. This is an open-access article distributed under the terms of the Creative Commons Attribution License, which permits unrestricted use, distribution, and reproduction in any medium, provided the original author and source are credited. 